\title{
1 Analytical Design Model for Reinforced Concrete Beams Strengthened in Shear Using L-Shaped CFRP Plates
}

\author{
Amir Mofidi ${ }^{1}$, Omar Chaallal ${ }^{2}$, and Yixin Shao ${ }^{3}$
}

\section{Abstract}

This paper presents the results of an analytical study on reinforced concrete (RC) T-beams strengthened in shear with L-shaped fiber-reinforced polymer (FRP) plates. The main objective of this study is to develop design equations for RC beams retrofitted in shear using L-shaped FRP plates, considering all possible modes of failure in ultimate limit states. Unlike RC beams strengthened with EB FRP plates and fabrics, prefabricated L-shaped plates feature unconventional failure modes due to their special shape and anchorage. The possible failure modes for RC beams strengthened with L-shaped FRP plates are: 1) Concrete breakout at the embedded part of the FRP plate in the flange; 2) FRP pull-off at the epoxy/FRP interface; 3) FRP pull-off at the concrete/epoxy interface; and 4) FRP overlap failure at the beam soffit. These failure modes do not occur in RC beams shear-strengthened with EB FRP fabrics and plates. Therefore, the existing design models for EB FRP fabrics and plates cannot predict with

${ }^{1}$ Postdoctoral Fellow, Department of Civil Engineering and Applied Mechanics, McGill University, 817 Sherbrooke West, Montreal QC Canada H3A 0C3. E-mail: amir.mofidi@mail.mcgill.ca

${ }^{2}$ Professor of Construction Engineering, University of Quebec, École de Technologie Supérieure, 1100 Notre-Dame West, Montreal QC Canada H3C $1 \mathrm{~K} 3$ (corresponding author). E-mail: omar.chaallal@etsmtl.ca

3 Associate Professor, Department of Civil Engineering and Applied Science, McGill University, Sherbrooke West, Quebec, Canada H3A 0C3. E-mail: yixin.shao@mcgill.ca 
20 sufficient accuracy the contribution of FRP to the shear resistance of RC beams shear-

21 strengthened with L-shaped plates. In this article, new design equations are proposed in light of

22 recent developments and data. These equations distinguish the failure mode and calculate the

23 FRP contribution to the shear resistance of RC beams strengthened with L-shaped FRP plates. In

24 some cases, full embedment of the L-shaped CFRP plates in the RC beam flange is not feasible

25 due to the presence of an obstacle (e.g., longitudinal reinforcing steel bars in the flange). The

26 new design equations are applicable to RC beams strengthened with L-shaped FRP plates with

27 different embedment lengths (including no embedment) of the CFRP plates in the RC beam

28 flange. The proposed design equations are validated against experimental data collected from the 29 literature.

30

31 CE Database subject headings: Concrete beam; Fiber-reinforced polymer; Strengthening;

32 Shear; Epoxy bonding; Debonding; Embedment; L-shaped plates; Design equations.

\section{INTRODUCTION}

35 Recently, significant interest has been shown in the application of fiber-reinforced polymer 36 (FRP) composites for strengthening and repair of existing reinforced concrete (RC) beams. 37 During the past two decades, several valuable research studies have been completed on the 38 shear-strengthening of RC beams with FRP composites using different methods. These methods 39 include externally bonded (EB) FRP sheets, near-surface mounted (NSM) FRP rods, and 40 embedded-through section (ETS) FRP rods (e.g., Uji 1992; Chaallal et al. 1998; Khalifa et al. 41 1998; Triantafillou 1998; De Lorenzis and Nanni 2001; Galal and Mofidi 2010; Chaallal et al. 42 2011). Meanwhile, to obtain a better insight into the behavior of FRP sheets and rods bonded to 
43 concrete members, a large number of pull-off tests have been conducted worldwide (e.g., Maeda

44 et al. 1997; Brosens and van Gemert 1999; Blaschko 2003; Seracino et al. 2007a). This

45 undertaking has been particularly valuable for shear-strengthening, where bonding is critical.

46 Based on experimental results, several bond models have been proposed to predict the bond

47 behavior of FRP/concrete joints for EB FRP sheets, NSM FRP rods, and ETS FRP rods (e.g.,

48 Neubauer and Rostásy 1997; Maeda et al. 1997; Chen and Teng 2001; Blaschko 2003; De

49 Lorenzis 2004; Yao et al. 2005; Seracino et al. 2007b; De Lorenzis and Teng 2007; Mofidi et al.

50 2012a). The FRP/concrete bond models have helped researchers to propose design equations for

51 RC beams strengthened in shear with FRP composites by means of EB FRP sheets, NSM FRP

52 rods, and ETS FRP rods (e.g., Khalifa et al. 1998; Chen and Teng 2003; Monti and Liotta 2006;

53 Rizzo and De Lorenzis 2009; Mofidi and Chaallal 2011a; Mofidi et al. 2012a). However, there

54 are very few research studies on the behavior of Adhesively Post-installed Embedded (APE)

55 FRP plates bonded to concrete members. In particular, to the authors' knowledge, no studies on

56 the bond strength of L-shaped FRP plate/concrete joints are available, and few investigations

57 have been carried out on the retrofit of RC beams in shear with L-shaped FRP plates.

58 Meier (1998) experimentally investigated the strength of L-shaped FRP/concrete joints.

59 Experimental tests on RC beams strengthened with L-shaped plates under static and cyclic 60 loadings have been reported in Czaderski (1998), EMPA report No. 116/7 (2002), Czaderski and 61 Motavalli (2004), Robertson (2004), and Chen and Robertson (2004). Mofidi et al. (2013) 62 reported the experimental results of shear-strengthened RC beams using FRP L-shaped plates 63 with different embedment lengths of the L-shaped plates in the RC beams' flange.

64 EMPA Report No. 116/7 (2002) proposed a design equation to calculate the contribution of 65 CFRP L-shaped plates to shear resistance. Based on the truss model, this report recommended 
that the maximum tensile force in one CFRP L-shaped plate should be limited to $45 \mathrm{kN}$ for the

67 specific type of plate used in their study. Existing design models for RC beams shearstrengthened with externally bonded (EB) FRP flat plates, laminates or sheets are not applicable

69 to beams strengthened with L-shaped FRP plates. Indeed, unlike RC beams strengthened with EB FRP plates and fabrics, prefabricated L-shaped plates feature unconventional failure modes

71 due to their special shape and anchorage. The possible failure modes for RC beams strengthened

72 with L-shaped FRP plates are: flange anchorage failure modes (i.e. failure due to concrete 73 breakout at the flange, CFRP plate pull-off from the flange at the concrete/epoxy interface or 74 epoxy/FRP interface) and FRP overlap debonding failure mode. These failure modes do not 75 occur in RC beams shear-strengthened with FRP fabrics and plates. The main objective of this 76 study is to propose rational and accurate design equations to calculate the contribution of FRP to 77 shear resistance for different embedment lengths of L-shaped FRP plates and for all possible 78 failure modes of the strengthened RC beams.

79 In the current research study, a comprehensive, transparent, and rational design model has been 80 developed that incorporates different failure modes. These failure modes include: (1) concrete 81 breakout of the CFRP plate at the flange; (2) CFRP plate pull-off from the flange at the 82 epoxy/FRP interface; (3) CFRP plate pull-off from the flange at the concrete/epoxy interface; (4) 83 FRP plate debonding from the RC beam web and (5) debonding of the CFRP plate overlap at the 84 beam soffit. The results predicted using the proposed design equations are verified against the 85 experimental results presented by Mofidi et al. (2013) as well as those provided in EMPA Report 86 No. 116/7 (2002).

87

\section{Current Design Equations}


89 Czaderski and Motavalli (2004) used their own model proposed in EMPA Report No. 116/7

90 (2002) to predict the contribution of FRP to shear resistance for RC beams strengthened in shear

91 with L-shaped plates. According to their model, the nominal shear resistance at the ultimate limit

92 state, $V_{R}$, of RC beams retrofitted in shear with FRP L-shaped plates can be calculated simply by

93 adding the contribution of FRP, $V_{R, f}$, to that of concrete, $V_{R, c}$, and of steel, $V_{R, s}$, as follows:

$$
V_{R}=V_{R, c}+V_{R, s}+V_{R, f} .
$$

95 They recommended that, when calculating the state shear resistance at the ultimate limit, the contribution of concrete to shear can be neglected. They also suggested that the maximum tensile

97 force in one CFRP L-shaped plate should be limited to $45 \mathrm{kN}$ for the L-shaped plate that was used in their study. Therefore, the ultimate limit-state shear resistance of RC beams strengthened 99 with L-shaped plates was expressed as follows (Czaderski and Motavalli 2004):

$$
V_{R}=A_{s} \cdot f_{y} \cdot \frac{z_{s}}{s_{s}} \cdot \cot \alpha+F_{f} \frac{z_{f}}{s_{f}} \cdot \cot \alpha \quad \text { with: } F_{f}=45 \mathrm{kN} \text { and } \alpha \geq 45^{\circ} \text {, }
$$

101 where $A_{s}, f_{y}, z_{s}, s_{s}, \alpha, F_{f}, z$, and $s_{f}$ are respectively the cross-sectional area, yield strength, and 102 internal lever arm strength of the transverse-steel reinforcement; the transverse-steel spacing; the 103 shear crack inclination; the tensile force in the FRP L-shaped plates; the internal lever arm 104 strength of the L-shaped FRP plates; and the spacing of the L-shaped plates. In their model, it 105 was assumed that the lever arm strengths for steel and for FRP transverse reinforcement were 106 equal.

107 Basically, the model used the strut-and-tie model for transverse FRP reinforcement, limiting the 108 strain in the FRP to 0.0067. The FRP strain limit calculations were performed based on the 109 characteristics of the L-shaped CFRP plate used, i.e., plate thickness $t_{f}=1.4 \mathrm{~mm}$, plate width $w_{f}$ $110=40 \mathrm{~mm}$, and plate modulus of elasticity $E_{f}=120 \mathrm{GPa}$. 
111 It has been established in recent years that many parameters affect the maximum tensile force

112 and the effective strain in externally bonded FRP plates (Triantafillou 1998; Chen and Teng

113 2001; Mofidi and Chaallal 2011a). By holding the maximum tensile force in the L-shaped FRP

114 plates constant, the effect of these influential parameters is thereby excluded (e.g., the concrete

115 compressive strength, the L-shaped plate dimensions and tensile characteristics, the bond

116 characteristics of the epoxy, and the groove dimensions in the flange). In addition, the equations

117 proposed in EMPA Report No. 116/7 (2002) are not applicable to beams strengthened using L-

118 shaped FRP plates with no or partial embedment of the CFRP plates in the beam flange.

119

120 Proposed shear design equations

121 In this section, new design equations are proposed for RC beams strengthened in shear using L-

122 shaped CFRP plates. The design model is capable of predicting the shear contribution of FRP for

123 specimens strengthened with different embedment lengths of CFRP L-shaped plates. Moreover,

124 it can predict the possible failure modes of the strengthened RC beams using L-shaped CFRP

125 plates.

126 For RC beams retrofitted with L-shaped CFRP plates, the FRP contribution to shear resistance

127 can be written in the following form:

128

$$
V_{f}=\frac{2 t_{f} \cdot w_{f} \cdot E_{f} \cdot \varepsilon_{f e} \cdot d_{f v}}{s_{f}}
$$

129 where $t_{f}, w_{f}, E_{f}, d_{f v}, \varepsilon_{e f}$, and $s_{f}$ are respectively the FRP plate thickness, FRP plate width, FRP 130 plate modulus of elasticity, effective shear depth of the cross section, effective strain in the FRP 131 plate, and spacing between the L-shaped CFRP plates. The effective shear depth can be taken as 132 the greater of $0.72 h$ and $0.9 d$ as per CSA/S806 (2012), where $h$ and $d$ are respectively the cross- 
133 sectional height and effective depth of the RC beams. The FRP effective strain is the maximum

134 strain experienced by the FRP at the ultimate point. Reliable predictions of the effective strains

135 for all potential failure modes of the specimen constitute an important step towards achieving

136 accuracy in calculating the FRP shear contribution at the ultimate loading stage. The maximum

137 strain in the FRP plate on each side of a shear crack occurs at the location where the FRP has the

138 greatest bond resistance. The corresponding effective strain in the FRP at the ultimate point due

139 to the applicable failure modes should be evaluated on each side of the major shear crack. The

140 failure occurs on the side with the lesser effective strain corresponding to an applicable failure

141 mode. Therefore, the value of the lesser effective strain should be used in Eq. 3 to calculate the

142 contribution of FRP to shear resistance.

143 Debonding of FRP sheets and plates is a common failure mode for RC beams strengthened using

144 FRP sheets without end-anchorage or FRP plates without embedment of the FRP plate in the

145 beam flange (Mofidi and Chaallal 2011b; Mofidi et al. 2012b). For retrofitted RC beams with

146 partially or fully embedded L-shaped FRP plates, embedment failure of the FRP plates should be

147 considered as a probable failure mode. The embedment failure of the CFRP plate in the RC beam

148 flange can be due to: (i) concrete breakout failure, (ii) CFRP plate pull-off at the epoxy/FRP

149 interface, or (iii) CFRP plate pull-off at the concrete/epoxy interface. Bond failure in the

150 overlapping legs of the CFRP plates at the beam soffit can be another possible failure mode.

151 Failure due to debonding of CFRP plates from the web

152 For RC beams strengthened using L-shaped FRP plates with no embedment (similar to EB FRP

153 U-jackets with no end anchorage), the bonding force developed in the FRP due to epoxy bonding 
154 of the FRP plate or sheet to the web can be calculated using a model proposed by Mofidi and 155 Chaallal (2011a) as follows:

$$
k_{c} k_{L} k_{w} L_{e} w_{f} \tau_{e f}=t_{f} w_{f} E_{f} \varepsilon_{f e},
$$

158 and hence:

$$
\varepsilon_{f e-w}=\frac{k_{c} \cdot k_{L} \cdot k_{w} \cdot \tau_{e f} \cdot L_{e}}{t_{f} \cdot E_{f}}=0.31 k_{c} \cdot k_{L} \cdot k_{w} \sqrt{\frac{\sqrt{f_{c}^{\prime}}}{t_{f} E_{f}}} \leq \varepsilon_{u f},
$$

160 where $\varepsilon_{f e-w}, k_{c}, k_{L}, k_{w}, \tau_{e f}$, and $L_{e}$ are respectively the effective strain in the FRP plate 161 corresponding to the bond between the FRP plate or sheet to the RC beam web, the concrete162 cracking coefficient based on transverse-steel and FRP rigidity values, a coefficient to 163 compensate for insufficient FRP anchorage length, the FRP width-to-spacing ratio coefficient, 164 the bond shear stress at failure, and the effective bond length. For details on calculations of $k_{c}, k_{L}$, 165 and $k_{w}$, see Mofidi and Chaallal (2011a,b). The effect of transverse steel on the FRP contribution 166 to shear resistance for RC beams shear-strengthened with L-shaped FRP plates was not 167 investigated. Therefore, $k_{c}$ is set to 1 in Eq. 6 in this article. Note that in any case, the effective 168 strain in the FRP should not exceed the threshold of 0.006 to secure concrete integrity through 169 aggregate interlocking mechanisms (fib 2001).

170 Failure due to concrete breakout at the flange:

171 Figure 1 presents possible embedment failure modes for CFRP plates bonded to the grooves in 172 the concrete flange. Concrete breakout at the RC beam flange (Fig. 1-a) takes place when the 173 CFRP plate develops a concrete failure cone. The failure occurs entirely in the concrete when the 
174 stresses in the failure zone reach the concrete tensile strength. This failure mode can be more 175 often expected in partially than in fully embedded CFRP plates.

176 Fuchs et al. (1995) proposed the concrete capacity design (CCD) approach for anchors in concrete, 177 which included the behavioral model for concrete breakout failure. Considering the concrete178 breakout failure mode, the model calculates the failure loads of cast-in-place or post-installed 179 mechanical anchors in tension or in shear. The concrete-breakout model proposed by Fuchs et al. 180 (1995) was later verified by Eligehausen et al. (2006) for anchors adhesively bonded to concrete. 181 According to their model, the mean concrete breakout capacity for adhesively post-installed 182 embedded anchors in an uncracked concrete $\left(P_{f b}\right)$ can be calculated as follows:

$$
P_{f b}=14.7 \sqrt{f_{c}^{\prime}}\left(k_{e l} \cdot L_{m b}\right)^{1.5}
$$

where $f_{c}^{\prime}, k_{e l}, L_{m b}$ are respectively the compressive strength of concrete in MPa, a coefficient to compensate for embedment lengths greater than the effective bond length of the plate, and the embedded length of the FRP plate in mm. Until further data on APE FRP plates bonded in concrete 187 grooves are made available, Eq. 7 can be used to calculate the concrete breakout capacity of APE FRP plates. It is assumed that the bond stresses are uniformly distributed around the FRP-plate cross section. In Eq. 7, the embedded length of the FRP plates is limited to the effective bond length of the FRP plate. Since the concrete breakout failure mode takes place in concrete, this failure mode may seem not related the bond between the concrete and FRP. However, it should be noted that the tensile force applied to the FRP plate is transferred to concrete through the shear bond stresses along the APE FRP plate. This is when the concrete cone forms based on CCD model resulting thereby on 194 a concrete breakout failure mode. According to the CCD model, there is a critical embedment depth, later termed the effective embedment depth, which plays an important role in forming the concrete 196 cone (Fuchs et al. 1995). On the other hand, for APE FRP plates, the maximum length of the 
197 embedded plate in the concrete that transfers the shear bond stresses is the effective bond length of 198 the FRP. Therefore, only the length of the APE FRP plate that is under bond stresses was used in the 199 CCD model. Obviously, the extra length of the APE FRP plate longer than the effective bond length 200 of FRP does not have a significant role in forming the concrete cone. It should be noted that similar 201 effective embedment lengths are considered in CCD model for other types of embedded anchors 202 and plates (see Fuchs. et al. 1995).

203 To this end, $k_{e l}$ is given by the following equations:

$$
k_{e l}=\left\{\begin{array}{ll}
1 & \text { if } L_{m b} \leq L_{e f} \\
L_{e f} / L_{m b} & \text { if } L_{m b}>L_{e f}
\end{array}\right\},
$$
where $L_{e f}$ is the effective bond length of the FRP plate. The effective bond length is the length 206 beyond which any increase in bond length does not translate into an increase in bond force. The 207 concept of effective bond length has been comprehensively discussed by many researchers for externally-bonded FRP (EB FRP) plates and near-surface mounted (NSM) bars and plates (e.g., 209 Neubauer and Rostásy 1997, Maeda et al. 1997, Chen and Teng 2001, De Lorenzis and Nanni 2001; Mofidi and Chaallal 2011a). The equation to calculated the effective bond length for FRP plates 211 proposed by Neubauer and Rostásy (1997) shows good correlation with experimental results based 212 on direct pull-off tests of EB plates (Chen and Teng 2001). Neubauer and Rostásy (1997), and also 213 other researchers (e.g. Nakaba et al. 2001 and Ulaga et al. 2003), investigated experimentally the 214 bond behavior at the FRP/concrete interface FRP plates using double-lap tension tests. In these tests 215 the FRP plate is sandwiched/bonded between/to two concrete prisms. On the other hand, Meier 216 (1998) conducted pull-off test series on APE FRP epoxy bonded to concrete (Fig. 2). It can be seen 217 that APE FRP plated bonded to concrete grooves pullout test is very similar to double-lap tension 
218 tests. Therefore, it was deemed reasonable to implement the equation proposed by Neubauer and

219 Rostásy (1997) to calculate the effective length of APE FRP plates.

220 In addition, this article shows in the following sections that the equation proposed by Neubauer and

221 Rostásy (1997) shows a reasonable correlation with experimental results based on direct pull-off

222 tests of NSM plates. This indicates that the surrounding concrete does not influence the effective

223 length of the FRP.

224 It should be mentioned that the effect of concrete confinement, although important for embedded

225 FRP reinforcement (i.e. no epoxy bonding), may not have a significant effect on EB and APE FRP.

226 Nevertheless, more experimental investigations are required to fully verify Eq. 9 for APE FRP

227 plates bonded to concrete grooves.

228 Meanwhile and until further data is made available, Eq. 9 can be used to calculate $L_{e f}$ for APE FRP 229 plates in concrete:

$$
L_{e f}=\sqrt{\frac{E_{f} \cdot t_{f}}{2 \sqrt{f_{c t}}}},
$$

231 where $f_{c t}$ is the concrete tensile strength, which can be calculated as a function of $f_{c}^{\prime}$ (Mirza et

232 al. 1979) as follows:

$$
f_{c t}=0.53 \sqrt{f_{c}^{\prime}}
$$

Moreover, the FRP effective strain corresponding to the concrete breakout failure mode can be 236 calculated using the equilibrium conditions in the FRP plate. Before concrete breakout, the force in 237 the FRP plate is equal to the maximum tensile resistance in the concrete. In the case where failure is 238 due to concrete breakout, the force developed in the FRP plate, $P_{\max }$, can be calculated using Eq. 11:

$$
P_{f b}=P_{\max }=A_{f} \cdot f_{e f} .
$$


240 The effective FRP strain corresponding to the concrete breakout failure mode can be determined

241 from the following equation:

$$
\varepsilon_{e f-b}=\frac{14.7 \sqrt{f_{c}^{\prime}}\left(k_{e l} \cdot L_{m b}\right)^{1.5}}{t_{f} w_{f} E_{f}} .
$$

244 Failure due to CFRP plate pull-off from the flange at the epoxy/FRP interface

245 Pull-off failure is a failure that occurs when the FRP plate or a part of the FRP plate slides out 246 from the concrete (Fig. 1-b). In this mode, failure takes place mostly at the interface between the 247 epoxy and the FRP plate. The maximum bond stress in this failure mode is basically a function 248 of the shear strength of the epoxy and not of the concrete tensile strength.

249 Previous investigations have shown that the bond stress along embedded rods is nonlinearly 250 distributed (e.g., De Lorenzis 2004; Eligehausen et al. 2004). However, it has been shown that 251 the actual bond stress can be replaced by the maximum bond stress distributed along the 252 effective bond length of the FRP rod or plate (McVay et al. 1996, Cook et al. 1998, Meszaros 253 1999; De Lorenzis and Teng 2007). In this failure mode, the maximum bond stress ( $\left.\tau_{\max }\right)$ is 254 associated with the mean bond strength of each epoxy product ( $\left.\tau_{a f}\right)$. Therefore, the pull-off force 255 of the CFRP plate from the flange at the epoxy/FRP interface $\left(P_{f p}\right)$ can be calculated as follows:

$$
P_{f p}=2 \tau_{\max }\left(t_{f}+w_{f}\right) k_{e l} L_{m b} .
$$

257 Blaschko (2003) proposed an equation to calculate the maximum bond stress of CFRP strips 258 bonded into slits. The maximum bond stress for the embedded L-shaped CFRP plates failing due 259 to pull-off at the epoxy/FRP interface is given by the following equations proposed by Blaschko 260 (2003): 


$$
\tau_{\max }=0.2 \sqrt[4]{a_{e}^{\prime}} \cdot \tau_{a f} \leq \frac{7.4 \sqrt{f_{c}^{\prime}}\left(k_{e l} \cdot L_{m b}\right)^{1.5}}{t_{f}+w_{f}}
$$

262 where $a_{e}^{\prime}$ is the lesser of the distances between the centerline of the groove to the edge of the concrete specimen or to the edge of the next groove, in millimeters, and $\tau_{a f}$ is the shear strength of the epoxy in MPa. Note that the upper bound of the bond strength for the embedded CFRP 265 plates is limited by the concrete pull-off strength.

266 Therefore, the effective FRP strain corresponding to CFRP plate pull-off at the epoxy/FRP interface 267 can be calculated from the following equation:

$$
\varepsilon_{e f-p}=\frac{0.4 \sqrt[4]{a_{e}^{\prime}} \cdot \tau_{a f} \cdot k_{e l} \cdot L_{m b}}{E_{f}}\left(\frac{1}{t_{f}}+\frac{1}{w_{f}}\right) .
$$

270 Failure due to CFRP plate pull-off from the flange at the concrete/epoxy interface:

271 According to previous experimental pull-off tests on EB and NSM FRP plates, rupture at the 272 concrete/epoxy interface has been the major failure mode among all the failure modes considered 273 (Chen and Teng 2001; Blaschko 2003; Yao et al. 2005; Seracino et al. 2007a). Failure at the 274 concrete/epoxy interface is characterized by cracking in the concrete layer adjacent to the epoxy275 bonded layer (Fig. 1-c). The FRP plate ultimately debonds from the concrete surface with a thin 276 layer of the concrete (in some cases, only mortar with no aggregate attached to the FRP). Most 277 experimental studies have been based on direct pull-off tests of EB FRP rods and plates or NSM 278 FRP rods or strips. Several analytical and experimental bond models have been proposed for EB 279 FRP rods and plates or NSM FRP rods or strips (e.g., Neubauer and Rostásy 1997; Maeda et al. 280 1997; Chen and Teng 2001; De Lorenzis 2004; De Lorenzis and Teng 2007). To the authors’ 281 knowledge, no bond models exist that are applicable to APE FRP plates in concrete grooves. 
282 Among the bond models mentioned, that proposed by Seracino et al. (2007b) model is applicable

283 to both EB and NSM FRP plates. According to Seracino et al. (2007b), their analytical model, 284 which uses a linear softening bond-slip relationship, is applicable to any adhesively bonded plate 285 and material. In this article, slight modifications were made to the Seracino et al. (2007b) model 286 to make it completely applicable to APE FRP plates bonded to concrete. Therefore, the pull-off 287 force of the CFRP plate from the flange at the concrete/epoxy interface $\left(P_{f c}\right)$ can be calculated 288 289 based on the Seracino et al. (2007b) model as follows:

$$
P_{f c}=0.85 \varphi_{f}^{0.25} \cdot f_{c}^{\prime 0.33} \sqrt{L_{p e r} E_{f} A_{f}},
$$

290 291 295 mm (Fig. 3).

296

where $\varphi_{f}$ is the debonding-failure plane aspect ratio and is equal to $d_{f} / b_{f}$. In the calculation of $\varphi_{f}$, $b_{f}$ is the length of the failure plane parallel to the concrete surface, which for NSM plates is taken to be the width of the groove $+2 \mathrm{~mm}$. In addition, $d_{f}$ is the length of the failure plane perpendicular to the concrete surface, which for NSM plates is taken to be the depth of the groove $+1 \mathrm{~mm}$. This formula is modified for APE FRP plates to be the depth of the groove +2

Furthermore, $L_{p e r}$ is the debonding failure plan in cross section, which is here taken to be $2\left(d_{f}+\right.$ $\left.b_{f}\right)$ for APE plates. The proposed equation to calculate the pull-off force of the CFRP plate at the concrete/epoxy interface (Eq. 16) assumes that the effective length of the CFRP plate is fully available. The pull-off force of the CFRP plate at the concrete/epoxy interface is a linear function of the embedment length, where the effective length represents the upper bound of the FRP bond length (Oehlers and Seracino 2004; Seracino et al. 2007a). Therefore, the following modifications can be made to include the effect of effective bond length on the model:

$$
P_{f c}=\frac{0.85 k_{e l} \cdot L_{m b} \cdot \varphi_{f}^{0.25} \cdot f_{c}^{\prime 0.33} \sqrt{L_{p e r} E_{f} A_{f}}}{L_{e f}} .
$$


304 It follows that the effective FRP strain corresponding to the CFRP plate pull-off at the 305 concrete/epoxy interface is:

$$
\varepsilon_{e f-c}=\frac{0.85 k_{e l} \cdot L_{m b} \cdot \varphi_{f}^{0.25} \cdot f_{c}^{\prime 0.33} \sqrt{L_{p e r}}}{L_{e f} \sqrt{E_{f} A_{f}}} .
$$

307 The effective length of the NSM FRP plates based on Seracino et al. (2007b) is given by the 308 following equations:

$$
\begin{gathered}
L_{e f}=\frac{\pi}{2 \lambda} ; \quad \lambda^{2}=\frac{\tau_{\max } L_{p e r}}{\delta_{\max } E_{f} A_{f}} \\
\tau_{\max }=\left(0.802+0.078 \varphi_{f}\right) f_{c}^{\prime 0.6} ; \quad \delta_{\max }=\frac{0.976 \varphi_{f}{ }^{0.526}}{0.802+0.078 \varphi_{f}},
\end{gathered}
$$

311 where $\lambda$ is a constant, and $\tau_{\max }$ and $\delta_{\max }$ are respectively the maximum shear stress and the 312 maximum slip, assuming a bilinear bond-slip relationship at the concrete/epoxy interface. The 313 maximum shear stress and the maximum slip are calculated on the basis of an empirical equation 314 extracted from a statistical analysis.

315 The results of the equations proposed by Seracino et al. (2007b) to calculate the effective bond 316 length of NSM plates are compared with those from the equations proposed by Neubauer and 317 Rostásy (1997) to calculate the effective bond length of EB FRP plates (Eq. 9). The results of 318 experimental studies using push-pull tests on NSM FRP strip-to-concrete joints by Seracino et al. 319 (2007a) were compared with the calculated effective lengths for each specimen, using the 320 equations just mentioned. Figure 4 shows that the results calculated by the Seracino et al. 321 (2007b) and the Neubauer and Rostásy (1997) models are in good agreement with each other $322\left(R^{2}=0.88\right)$. In this article, the equations by Neubauer and Rostásy (1997), which assume a 323 bilinear shear-slip model for FRP plates bonded to concrete (similarly to the assumption in 
324 Seracino et al. 2007b), are used to determine the effective bond length. It is thought that the

325 Neubauer and Rostásy (1997) model offers a more direct approach to the calculation of effective

326 bond length than the Seracino et al. (2007b) model.

327

328 Failure due to debonding of overlapping CFRP plates from the soffit

329 Debonding of overlapping CFRP plates at the soffit of an RC beam shear-strengthened with L330 shaped FRP plate is one possible failure mode. The development length of the L-shaped FRP 331 plates bonded to the beam soffit $\left(L_{d v}\right)$ should be determined so as to prevent debonding of the 332 CFRP plate overlap.

333 Although the bond stress along the leg of the L-shaped plate bonded to the web is nonlinearly 334 distributed, the actual bond stress can be replaced by the maximum bond stress distributed along 335 the effective bond length of the FRP plate. In this way, the effect of the leg of the L-shaped plate 336 bonded to the beam soffit can be considered to distribute the bond stresses linearly through the 337 bond between the leg of the CFRP plate and the beam soffit. This translates into an increase in 338 the effective bond area of the CFRP plate. Therefore, the bond strength can be calculated by 339 introducing the effective bond area of the CFRP plate (Fig. 5), and the load required to debond 340 the CFRP plate overlap from the beam soffit $\left(P_{f_{0}}\right)$ can be calculated as follows:

$$
P_{f o}=\left[L_{e} \cdot \min \left(L_{d v}, L_{e}\right)-0.5\left(L_{e}-w_{f}\right)\left(\min \left(L_{d v}, L_{e}\right)-w_{f}\right)\right] \cdot \tau_{e f},
$$

342 where $\tau_{e f}$ can be equated to the concrete tensile strength $\left(f_{c t}\right)$. The effective FRP strain corresponding 343 to overlap debonding of the CFRP L-shaped plate from the beam soffit can be calculated using the 344 following equation:

$$
\varepsilon_{f e-o}=\frac{\left[L_{e} \cdot \min \left(L_{d v}, L_{e}\right)-0.5\left(L_{e}-w_{f}\right)\left(\min \left(L_{d v}, L_{e}\right)-w_{f}\right)\right] \cdot \tau_{e f}}{2 t_{f} E_{f} w_{f}} .
$$


346 Note that the effective strain in the FRP plate at ultimate load can be calculated as:

$$
\varepsilon_{f e-u}=\min \left(\varepsilon_{f e-w}+\min \left(\varepsilon_{f e-b}, \varepsilon_{f e-p}, \varepsilon_{f e-c}\right), \varepsilon_{f e-o}\right) .
$$

\section{Verification of the proposed design proposals}

350 Currently, few pullout tests have been performed on APE FRP plates bonded to concrete grooves 351 or to shear-strengthened RC beams using L-shaped FRP plates. As previously mentioned, Meier 352 (1998) conducted a direct pullout test series on APE FRP plates bonded to concrete grooves (Fig. 2-a) and on L-shaped plates bonded to concrete block joints (Fig. 2-b). In this article, the experimental results proposed by Meier (1998) are compared with the calculated results based on the proposed equations (see Table 1). The calculated values of the pullout strength of FRP plates 356 corresponding to each failure mode are shown in Table 1. The failure mode of each specimen 357 was determined based on the corresponding calculated pullout force. Moreover, the results of the 358 pullout tests described by Meier (1998) on L-shaped CFRP plate joints bonded to concrete 359 blocks are compared with the results extracted from the proposed equations. Clearly, more experimental data are needed to perform a full validation of the proposed equations.

361 Nevertheless, the predicted results for the pullout strength of APE FRP plates bonded to concrete 362 grooves and of L-shaped FRP plates bonded to concrete blocks show a good correlation with the 363 experimental results $\left(R^{2}=0.98\right)$.

364 In another investigation, the experimental contributions of FRP to the shear resistance of the 365 retrofitted specimens in this study were compared with the shear resistance predicted by the 366 proposed equations (see Table 2). The calculated values of effective strain developed in the FRP 367 plates corresponding to each failure mode are shown in Table 2. The prevalent failure mode can 368 thus be identified. The FRP shear contribution was then calculated based on the critical effective 
369 strain of the governing failure mode. Finally, the experimental results reported by Mofidi et al.

370 (2013) and EMPA (2002) on RC beams shear-strengthened with L-shaped FRP plates are

371 compared to the results calculated using the proposed equations (see Table 2). It should be noted

372 that the shear resistance of the FRP corresponding to the calculated flexural failure load $\left(V_{f-f l x}\right)$

373 should be considered for the specimens that failed in flexure (S1-LS-FE and S4-EMPA). Overall,

374 the calculated results show a reasonable correlation with the experimental results $\left(R^{2}=0.69\right)$.

375

376 CONCLUSIONS

377 Based on the results of the current research study, the following major conclusions can be drawn:

378 - Comprehensive design equations for RC beams strengthened in shear with L-shaped FRP

379 plates are proposed. These equations consider various potential failure modes, including:

380 (1) concrete breakout at the flange, (2) CFRP plate pull-off from the flange at the 381 epoxy/FRP interface, (3) CFRP plate pull-off from the flange at the concrete/epoxy 382 interface, (4) debonding of FRP plate from the RC beam web, and (5) debonding of the 383 CFRP plate overlap at the beam soffit.

384 - The proposed design equations are expected to be applicable to any embedment length of 385 L-shaped FRP plates into the flange of RC beams. The effective application of partially 386 embedded L-shaped CFRP plates to shear-strengthen RC beams was verified based on the analytical design model.

- The predicted results of the design equations were validated using few available experimental results in the literature. 


\section{ACKNOWLEDGMENTS}

394 The authors wish to acknowledge the support provided by the Natural Sciences and Engineering 395 Research Council of Canada through a postdoctoral fellowship to Dr. Amir Mofidi and to Prof. Chaallal through a Discovery grant.

\section{REFERENCES}

399

400

401

402

403

404

405

406

407

408

409

410

411

412

413

414

415

416

417

418

419

420

421

422

Blaschko, M. (2003). Bond behavior of CFRP strips glued into slits. Proceedings, 6th International Symposium on Fiber-Reinforced Polymer Reinforcement for Concrete Structures, K.H. Tan (ed.), Singapore, 205-214.

Brosens, K. and Van Gemert, D. (1999). Anchorage design for externally bonded carbon-fiber polymer laminates, Proceedings, $4^{\text {th }}$ International Symposium on Fiber-Reinforced Polymer Reinforcement for Concrete Structures, Baltimore, United States, 635-645.

Chaallal, O., Mofidi, A., Benmokrane, B., and Neale, K. (2011). Embedded through-section FRP rod method for shear strengthening of RC beams: performance and comparison with existing techniques. Journal of Composites for Construction 15(3), 374-383.

Chaallal, O., Nollet, M.J., and Perraton, D. (1998). Strengthening of reinforced concrete beams with externally bonded fiber-reinforced plastic plates: design guidelines for shear and flexure. Can. J. Civil Eng. 25(4), 692-704.

Chen, J. and Robertson, I. (2004). Test of cracked pre-stressed concrete T-beam retrofitted for shear using CFRP L-shaped plates. University of Hawaii Research Report, UHM/CEE/04-06.

Chen, J.F. and Teng, J.G. (2001). Anchorage strength models for FRP and steel plates bonded to concrete. J. Struct. Eng. 127(7), 784-791.

Chen, J.F. and Teng, J.G. (2003). Shear capacity of FRP-strengthened RC beams: FRP debonding. Construction and Building Materials 17(1), 27-41.

Cook, R.A., Kunz, J., Fuchs, W., and Konz, R.C. (1998). Behavior and design of single adhesive anchors under tensile load in uncracked concrete. ACI Structural Journal 95(1), 9-26.

Czaderski, C. (1998). Nachträgliche Schubverstärkung mit CFK-Winkeln. Schweizer Ingenieur und Architekt (SI + A) 43(22), 822-826 (in German).

Czaderski, C. and Motavalli, M. (2004). Fatigue behavior of CFRP L-shaped plates for shear strengthening of RC T-beams. Composites: Part B 35, 279-290. 
423 De Lorenzis, L. (2004). Anchorage length of near-surface mounted fiber-reinforced polymer rods 424 for concrete strengthening —analytical modeling. ACI Struct. J. 101(3), 375-386.

425 De Lorenzis, L. and Nanni, A. (2001). Shear strengthening of reinforced concrete beams with 426 NSM fiber-reinforced polymer rods. ACI Struct. J. 98(1), 60-68.

427 De Lorenzis, L. and Teng, J.G. (2007). Near-surface mounted FRP reinforcement: an emerging 428 technique for structural strengthening. Composites: Part B 38, 119-143.

429 EMPA Test Report 116/7 (2002). Shear strengthening with prefabricated CFRP L-shaped plates: 430 test beams S1 to S6. Eidgenössische Materialprüfungs- und Forschungsanstalt, 79 pages.

431 Eligehausen, R., Appl, J.J., Lehr, B., Meszaros, J., and Fuchs, W. (2004). Tragverhalten und 432 Bemessung von Befestigungen mit Verbunddübeln unter Zugbeanspruchung, Part 1: Einzeldübel 433 mit großem Achs- und Randabstand. Beton und Stahlbetonbau 99(7), 561-571 (in German).

434 Eligehausen, R., Cook, R.A., and Appl, J. (2006). Behavior and design of adhesive bonded 435 anchors. ACI Structural Journal 103(6), 822-831.

436 fib-TG 9.3 (2001). Externally Bonded FRP Reinforcement for RC Structures. International 437 Federation for Structural Concrete, Lausanne, Switzerland.

438 Fuchs, W., Eligehausen, R., and Breen, J.E. (1995). Concrete capacity design (CCD) approach 439 for fastening to concrete. ACI Structural Journal 92(1), 73-94.

441 anchored unbonded dry carbon fibre sheets. J. of Performance of Constructed Facilities 24(1), $442 \quad 31-39$.

443 Khalifa, A., Gold, W.J., Nanni, A., and Aziz, A. (1998). Contribution of externally bonded FRP 444 to shear capacity of RC flexural members. J. Compos. Constr. 2(4), 195-203.

445 Maeda, T., Asano, Y., Sato, Y., Ueda, T., and Kakuta, Y. (1997). A study on bond mechanism of 446 carbon fiber sheet. Proceedings, 3rd International Symposium on Non-Metallic (FRP) 447 Reinforcement for Concrete Structures, Sapporo, Japan, 1, 279-286.

448 McVay, M., Cook, R.A., and Krishnamurthy, K. (1996). Pullout simulation of post-installed 449 chemically bonded anchors. ASCE Journal of Structural Engineering 122(9), 1016-1024.

450 Meier, H., (1998). CFK-Schubverstärkungselemente. Schweizer Ingenieur und Architekt (SI + A) 451 43(22), 819-821 (in German).

452 Meszaros, J. (1999). Tragverhalten von Verbunddübeln im ungerissenen und gerissenen Beton. 453 Doctoral thesis, University of Stuttgart, Stuttgart, Germany (in German).

454 Mirza, S., MacGregor, J., and Hatzinikolas, M. (1979). Statistical descriptions of strength of 455 concrete. J. Struct. Div. 105(6), 1021-1037. 
Mofidi, A. and Chaallal, O., (2011a), Renforcement à l'effort tranchant des poutres en béton armé à l'aide de matériaux composites collés en surface: Avancées et perspectives pour la norme CSA-S806. Can. J. Civil Eng. 38, 556-569.

Mofidi, A. and Chaallal, O. (2011b). Shear strengthening of RC beams with externally bonded FRP composites: effect of strip-width to strip-spacing ratio. Journal of Composites for Construction 15(5), 732-742.

Mofidi, A., Chaallal, O., Benmokrane, B., and Neale, K.W. (2012a). Performance of endanchorage systems for RC beams strengthened in shear with epoxy-bonded FRP. Journal of Composites for Construction 16(3), 322-331.

Mofidi, A., Chaallal, O., Benmokrane, B., and Neale, K.W. (2012b). Experimental tests and design model for RC beams strengthened in shear using the embedded through-section FRP method. Journal of Composites for Construction 16(5), 540-550.

Mofidi, A., Thivierge, S., Chaallal, O., and Shao, Y. (2013). Performance of Reinforced Concrete Beams Strengthened in Shear Using L-Shaped CFRP Plates - An Experimental Investigation. Journal of Composites for Construction, doi:10.1061/(ASCE)CC.19435614.0000398 .

Monti, G. and Liotta, M. (2006). Tests and design equations for FRP strengthening in shear. Construction and Building Materials 21, 799-809.

Nakaba, K., Kanakubo, T., Furuta, T. and Yoshizawa, H. (2001). Bond Behavior between Fiberreinforced Polymer Laminates and Concrete, ACI Structural Journal, 98(3), 359-367.

Neubauer, U. and Rostásy, F.S. (1997). Design Aspects of Concrete Structures Strengthened with Externally Bonded CFRP Plates. ECS Publications, Edinburgh, 109-118.

Oehlers, D.J. and Seracino, R. (2004). Design of FRP and Steel-Plated Structures. Elsevier Science, Oxford, United Kingdom.

Rizzo, A. and De Lorenzis, L. (2009). Behavior and capacity of RC beams strengthened in shear with NSM FRP reinforcement. Constr. and Building Materials 23, 1555-1567.

Robertson, I., Johnson, G.P., and Sharma, B. (2007). Shear retrofit of concrete T-beams using CFRP. Proceedings, 8rd International Symposium on Fiber-Reinforced Polymers in Reinforced Concrete Structures, Patras, Greece.

Seracino, R., Jones, N.M., Ali, M.S.M., Page, M.W., and Oehlers, D.J. (2007a). Bond strength of near-surface mounted FRP strip-to-concrete joints. Journal of Composites for Construction 11(4), 401-409.

Seracino, R., Raizal Saifulnaz, M.R., and Oehlers, D.J. (2007b). Generic debonding resistance of EB and NSM plate-to-concrete joints. Journal of Composites for Construction 11(1), 62-70. 
490 Triantafillou, T.C. (1998). Shear strengthening of reinforced concrete beams using epoxy-bonded 491 FRP composites. ACI Struct. J. 95(2), 107-115.

492 Uji, K. (1992). Improving shear capacity of existing reinforced concrete members by applying 493 carbon fiber sheets. Trans. Jpn. Concr. Institute 14, 253-266.

494 Ulaga, T., Vogel, T. and Meier, U. (2003). Bilinear Stress-Slip Bond Model: Theoretical 495 Background and Significance, Proc. of the 6th Int. Symp. on on FRP Reinforcement for Concrete 496 Structures (FRPRCS-6), Vol. 1, pp. 153-162.

497 Yao, J., Teng, J.G., and Chen, J.F. (2005). Experimental study on FRP-to-concrete bonded joints. 498 Composites, Part B: Engineering 36(2), 99-113.

499

500

501

502

503

504

505

506

507

508

509

510

511

512

513 
515

516

517

Table 1 - Predicted results from proposed design equations versus experimental pullout results reported by Meier (1998).

\begin{tabular}{|c|c|c|c|c|c|c|}
\hline $\begin{array}{l}\text { Direct pullout } \\
\text { test type }\end{array}$ & $\begin{array}{l}\text { Bond } \\
\text { length, }\end{array}$ & $\begin{array}{l}\text { Experimental } \\
\text { load at } \\
\text { failure, }\end{array}$ & $\begin{array}{c}\text { Predicted } \\
\text { concrete } \\
\text { breakout } \\
\text { load, } \\
\text { kN } \\
\end{array}$ & $\begin{array}{c}\text { Predicted } \\
\text { pull-off } \\
\text { load at } \\
\text { epoxy/FRP } \\
\text { interface, } \\
\text { kN } \\
\end{array}$ & $\begin{array}{l}\text { Predicted pull- } \\
\text { off load at } \\
\text { concrete/epoxy } \\
\text { interface, } \\
\mathrm{kN}\end{array}$ & $\begin{array}{c}\text { Predicted } \\
\text { overlap } \\
\text { debonding } \\
\text { load, } \\
\text { kN } \\
\end{array}$ \\
\hline \multirow{3}{*}{$\begin{array}{l}\text { APE CFRP } \\
\text { plate/concrete } \\
\text { block joint }\end{array}$} & 100 & 77.0 & 84.5 & 166.3 & 70.3 & - \\
\hline & 150 & 100.0 & 126.2 & 249.7 & $\underline{105.5}$ & - \\
\hline & 200 & 121.0 & 190.4 & 285.8 & $\underline{121.0}$ & - \\
\hline \multirow{4}{*}{$\begin{array}{c}\text { L-shaped } \\
\text { CFRP } \\
\text { plate/concrete } \\
\text { block joint }\end{array}$} & 150 & 67.0 & - & - & - & $\underline{56.3}$ \\
\hline & 225 & 69.0 & - & - & - & $\underline{63.5}$ \\
\hline & 300 & 74.0 & - & - & - & $\underline{63.5}$ \\
\hline & & & & & & $R^{2}=0.98$ \\
\hline
\end{tabular}

Note: The underlined failure load is the calculated governing failure load of the FRP/concrete joint. 
Table 2 - Summary of calculated results versus experimental results for shear-strengthened RC

beams.

\begin{tabular}{|c|c|c|c|c|c|c|c|c|c|c|c|c|c|c|c|c|c|c|}
\hline $\begin{array}{c}\text { Speci } \\
\text { men } \\
\text { name/s } \\
\text { tudy }\end{array}$ & $\begin{array}{l}f_{c}^{\prime} \\
\stackrel{\mathrm{M}}{\mathrm{Pa}} \\
\end{array}$ & $\begin{array}{l}h, \\
\mathrm{~m} \\
\mathrm{~m}\end{array}$ & $\begin{array}{l}h_{f}, \\
\mathrm{~m} \\
\mathrm{~m}\end{array}$ & $\begin{array}{l}b_{w} \\
\dot{m} \\
\mathrm{~m}\end{array}$ & $\begin{array}{l}d, \\
\mathrm{~m} \\
\mathrm{~m}\end{array}$ & $\begin{array}{l}w_{f} \\
\text { m } \\
\mathrm{m}\end{array}$ & $\begin{array}{l}t_{f} \\
\mathrm{~m} \\
\mathrm{~m}\end{array}$ & $\begin{array}{l}s_{f}, \\
m \\
m\end{array}$ & $\begin{array}{l}E_{f}, \\
\text { G } \\
\mathrm{Pa}\end{array}$ & $\varepsilon_{f e-b}$ & $\varepsilon_{f e-p}$ & $\varepsilon_{f e-c}$ & $\varepsilon_{f e-o}$ & $\varepsilon_{f e-w}$ & $\varepsilon_{f-u}$ & $\begin{array}{l}V_{f-} \\
\text { cal, } \\
\mathrm{kN}\end{array}$ & $\begin{array}{l}V_{f-} \\
f l x, \\
\mathrm{kN}\end{array}$ & $\begin{array}{l}V_{f-} \\
\text { exp, } \\
\mathrm{kN}\end{array}$ \\
\hline $\begin{array}{l}\text { S1-LS- } \\
\text { NE } \\
\text { Mofidi } \\
\text { et al. } \\
2013\end{array}$ & $\begin{array}{c}33 \\
.7\end{array}$ & $\begin{array}{l}4 \\
0 \\
6\end{array}$ & $\begin{array}{l}1 \\
0 \\
2\end{array}$ & $\begin{array}{l}1 \\
5 \\
2\end{array}$ & $\begin{array}{l}3 \\
5 \\
0\end{array}$ & $\begin{array}{l}4 \\
0\end{array}$ & 2 & $\begin{array}{l}18 \\
7.5\end{array}$ & 90 & 0 & 0 & 0 & $\begin{array}{c}0.0 \\
058\end{array}$ & $\begin{array}{c}0.0 \\
018\end{array}$ & $\begin{array}{c}0.0 \\
018\end{array}$ & $\frac{42 .}{\underline{3}}$ & $\begin{array}{l}12 \\
4.5\end{array}$ & $\begin{array}{c}59 . \\
2\end{array}$ \\
\hline $\begin{array}{l}\text { S1-LS- } \\
\text { PE } \\
\text { Mofidi } \\
\text { et al. } \\
2013\end{array}$ & $\begin{array}{c}33 \\
.7\end{array}$ & $\begin{array}{l}4 \\
0 \\
6\end{array}$ & $\begin{array}{l}1 \\
0 \\
2\end{array}$ & $\begin{array}{l}1 \\
5 \\
2\end{array}$ & $\begin{array}{l}3 \\
5 \\
0\end{array}$ & $\begin{array}{l}4 \\
0\end{array}$ & 2 & $\begin{array}{l}18 \\
7.5\end{array}$ & 90 & $\begin{array}{r}0.0 \\
015\end{array}$ & $\begin{array}{c}0.0 \\
054\end{array}$ & $\begin{array}{c}0.0 \\
024\end{array}$ & $\begin{array}{c}0.0 \\
058\end{array}$ & $\begin{array}{c}0.0 \\
018\end{array}$ & $\begin{array}{c}0.0 \\
033\end{array}$ & $\frac{77 .}{\underline{9}}$ & $\begin{array}{l}12 \\
4.5\end{array}$ & $\begin{array}{c}84 . \\
1\end{array}$ \\
\hline $\begin{array}{l}\text { S1-LS- } \\
\text { FE } \\
\text { Mofidi } \\
\text { et al. } \\
2013\end{array}$ & $\begin{array}{l}33 \\
.7\end{array}$ & $\begin{array}{l}4 \\
0 \\
6\end{array}$ & $\begin{array}{l}1 \\
0 \\
2\end{array}$ & $\begin{array}{l}1 \\
5 \\
2\end{array}$ & $\begin{array}{l}3 \\
5 \\
0\end{array}$ & $\begin{array}{l}4 \\
0\end{array}$ & 2 & $\begin{array}{l}18 \\
7.5\end{array}$ & 90 & $\begin{array}{c}0.0 \\
119\end{array}$ & $\begin{array}{c}0.0 \\
216\end{array}$ & $\begin{array}{c}0.0 \\
096\end{array}$ & $\begin{array}{c}0.0 \\
058\end{array}$ & $\begin{array}{c}0.0 \\
018\end{array}$ & $\begin{array}{c}0.0 \\
058\end{array}$ & $\begin{array}{l}13 \\
8.9\end{array}$ & $\underline{\underline{12}}$ & $\begin{array}{l}11 \\
9.5\end{array}$ \\
\hline $\begin{array}{l}\text { S1-EB- } \\
\text { NA } \\
\text { Mofidi } \\
\text { et al. } \\
2013\end{array}$ & $\begin{array}{c}33 \\
.7\end{array}$ & $\begin{array}{l}4 \\
0 \\
6\end{array}$ & $\begin{array}{l}1 \\
0 \\
2\end{array}$ & $\begin{array}{l}1 \\
5 \\
2\end{array}$ & $\begin{array}{l}3 \\
5 \\
0\end{array}$ & $\begin{array}{l}\mathrm{n} / \\
\mathrm{a}\end{array}$ & $\begin{array}{l}0.1 \\
07\end{array}$ & $\mathrm{n} / \mathrm{a}$ & $\begin{array}{c}23 \\
1\end{array}$ & 0 & 0 & 0 & 0 & $\begin{array}{c}0.0 \\
048\end{array}$ & $\begin{array}{c}0.0 \\
048\end{array}$ & $\frac{74}{\underline{3}}$ & $\begin{array}{l}12 \\
4.5\end{array}$ & $\begin{array}{c}77 . \\
8\end{array}$ \\
\hline $\begin{array}{c}\text { S3 } \\
\text { EMPA } \\
2002\end{array}$ & $\begin{array}{l}28 \\
.0\end{array}$ & $\begin{array}{l}5 \\
0 \\
0\end{array}$ & $\begin{array}{l}1 \\
2 \\
0\end{array}$ & $\begin{array}{l}1 \\
5 \\
0\end{array}$ & $\begin{array}{l}3 \\
8 \\
0\end{array}$ & $\begin{array}{l}4 \\
0\end{array}$ & 1.4 & $\begin{array}{c}30 \\
0.0\end{array}$ & $\begin{array}{c}12 \\
0\end{array}$ & $\begin{array}{c}0.0 \\
158\end{array}$ & $\begin{array}{c}0.0 \\
274\end{array}$ & $\begin{array}{r}0.0 \\
115\end{array}$ & $\begin{array}{c}0.0 \\
058\end{array}$ & $\begin{array}{c}0.0 \\
018\end{array}$ & $\begin{array}{c}0.0 \\
058\end{array}$ & $\frac{89 .}{\underline{1}}$ & $\begin{array}{l}18 \\
7.1\end{array}$ & $\begin{array}{l}15 \\
4.5\end{array}$ \\
\hline $\begin{array}{c}\text { S4 } \\
\text { EMPA } \\
2002\end{array}$ & $\begin{array}{c}30 \\
.8\end{array}$ & $\begin{array}{l}5 \\
0 \\
0\end{array}$ & $\begin{array}{l}1 \\
2 \\
0\end{array}$ & $\begin{array}{l}1 \\
5 \\
0\end{array}$ & $\begin{array}{l}3 \\
8 \\
0\end{array}$ & $\begin{array}{l}4 \\
0\end{array}$ & 1.4 & $\begin{array}{c}30 \\
0.0\end{array}$ & $\begin{array}{c}12 \\
0\end{array}$ & $\begin{array}{c}0.0 \\
158\end{array}$ & $\begin{array}{c}0.0 \\
274\end{array}$ & $\begin{array}{r}0.0 \\
115\end{array}$ & $\begin{array}{c}0.0 \\
058\end{array}$ & $\begin{array}{c}0.0 \\
018\end{array}$ & $\begin{array}{c}0.0 \\
058\end{array}$ & $\begin{array}{c}89 . \\
1\end{array}$ & $\frac{24}{\underline{6}}$ & $\begin{array}{c}17 . \\
0\end{array}$ \\
\hline
\end{tabular}

Note: The underlined shear contribution of FRP is the $V_{f}$ corresponding to the calculated governing failure mode of the beam.

$\varepsilon_{f e-b}, \varepsilon_{f e-p}, \varepsilon_{f e-c}, \varepsilon_{f e-o}, \varepsilon_{f e-w}$, and $\varepsilon_{f e-u}$ are the effective FRP strains corresponding to concrete breakout, FRP pull-off at the epoxy/FRP interface, FRP pull-off at the concrete/epoxy interface, overlap debonding of the CFRP L-shaped plate, debonding of FRP from the web, and ultimate shear failure respectively. $V_{f-c a l}, V_{f-f l x}$ and $V_{\text {f-exp }}$ are the FRP shear contributions corresponding to the calculated effective strain at ultimate load, the values at flexural failure of the beam, and experimental results respectively. The effective strain of the FRP at ultimate load is given by: $\varepsilon_{f e-u}=\min \left(\varepsilon_{f e-w}+\min \left(\varepsilon_{f e-b}, \varepsilon_{f e-p}, \varepsilon_{f e-c}\right), \varepsilon_{f e-o}\right)$. 


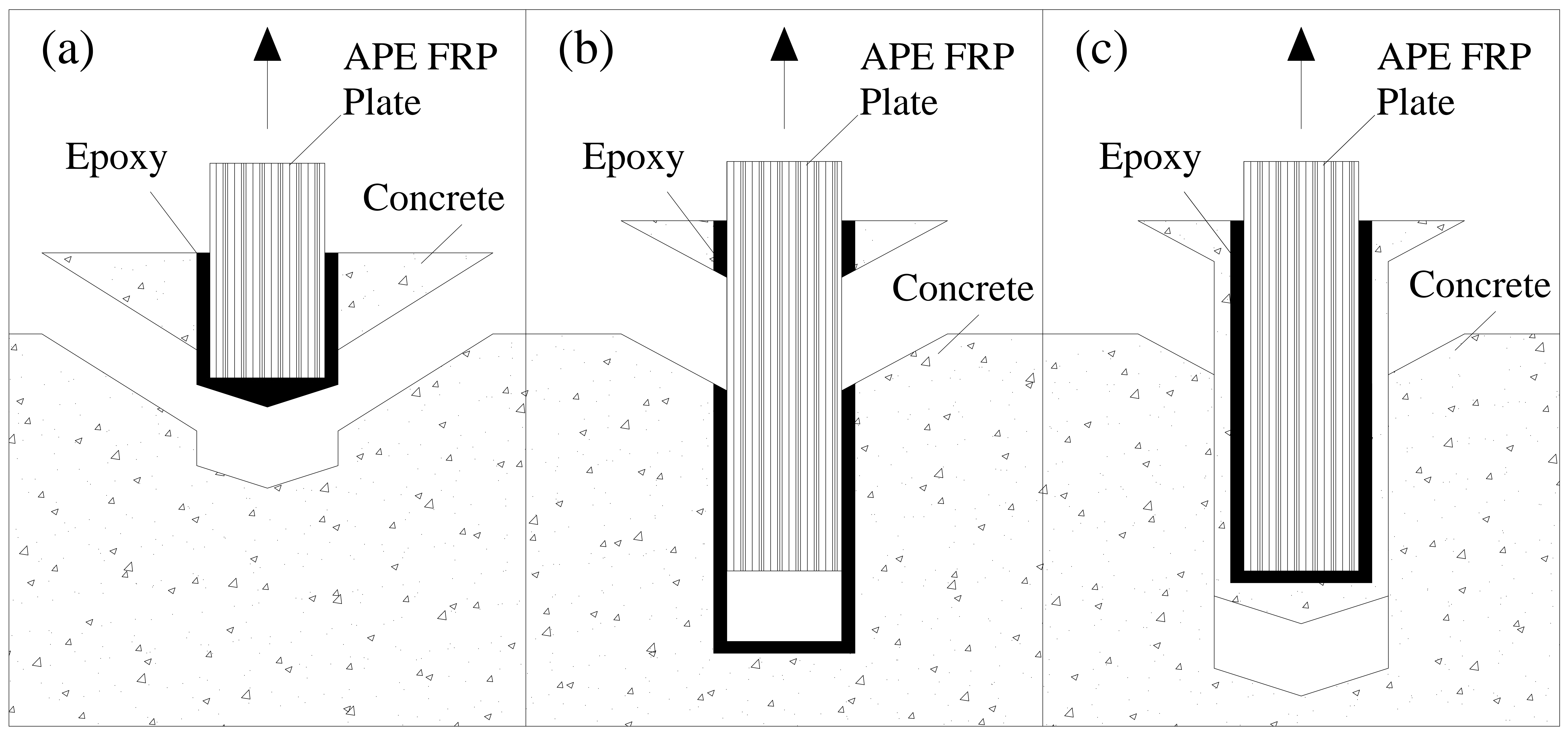


(a)

\section{APE FRP} Plate

Concrete

Epoxy (b) $\mathbf{\Delta}$

L-shaped FRP Plate Epoxy

Concrete
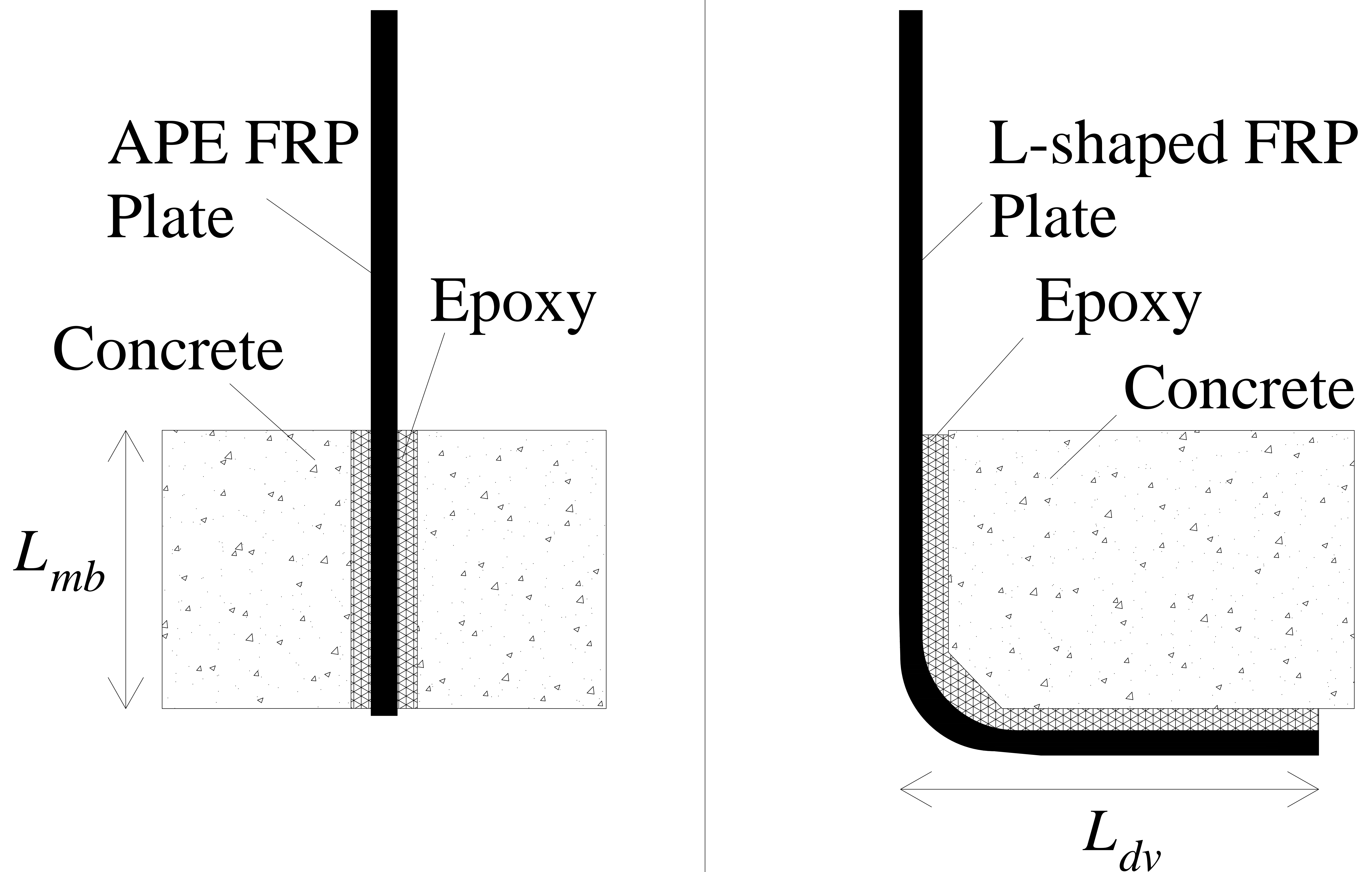


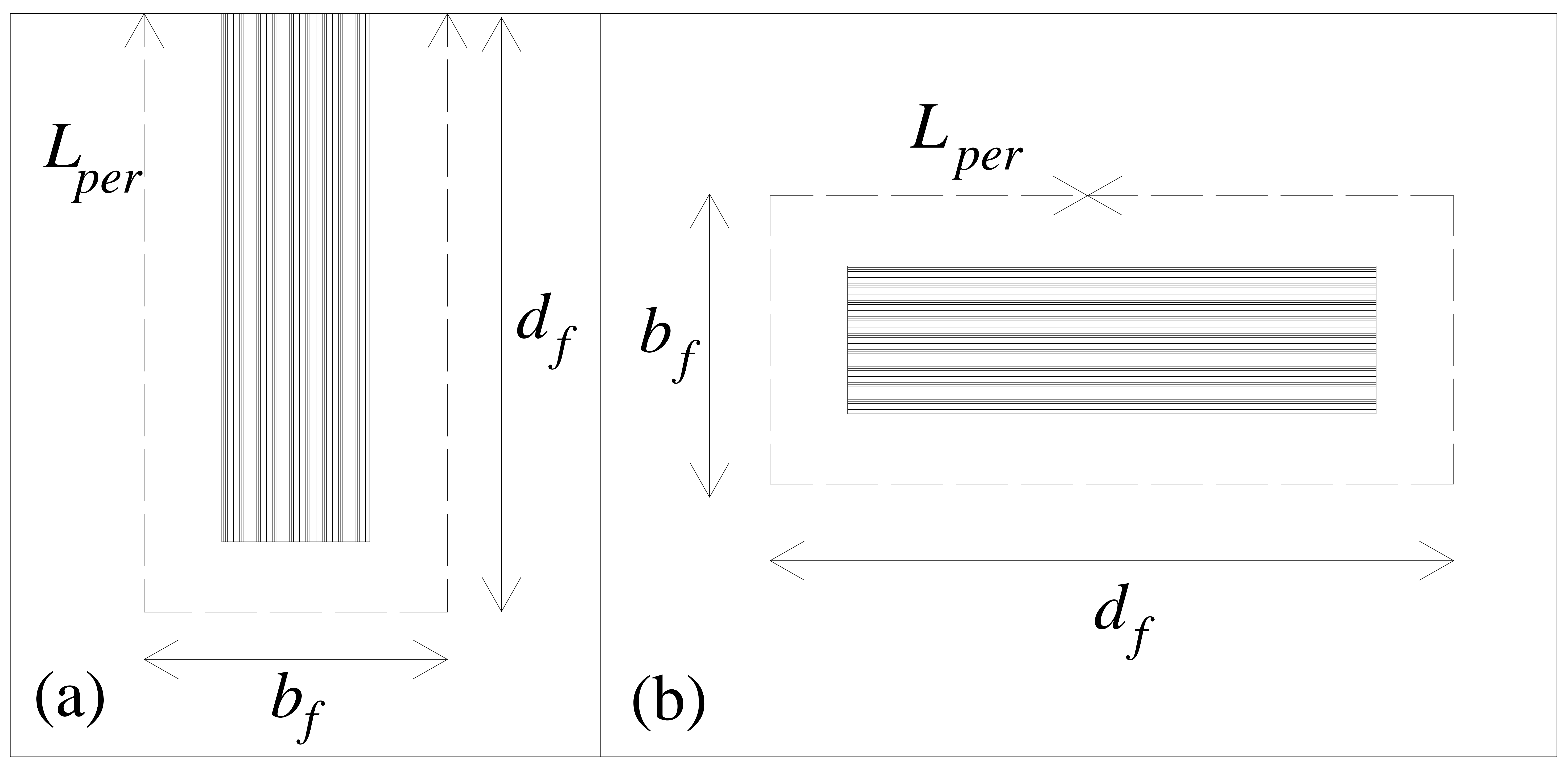




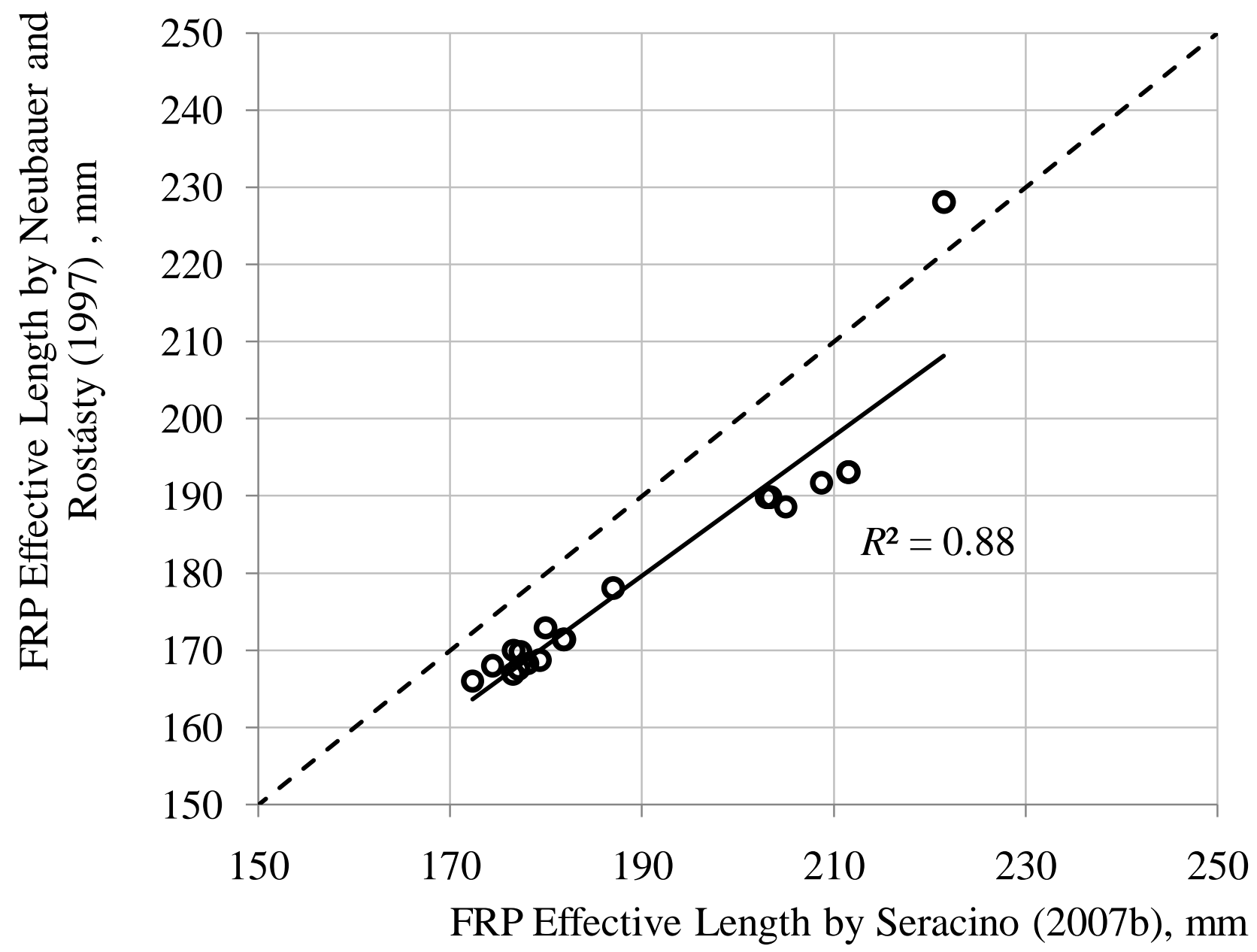




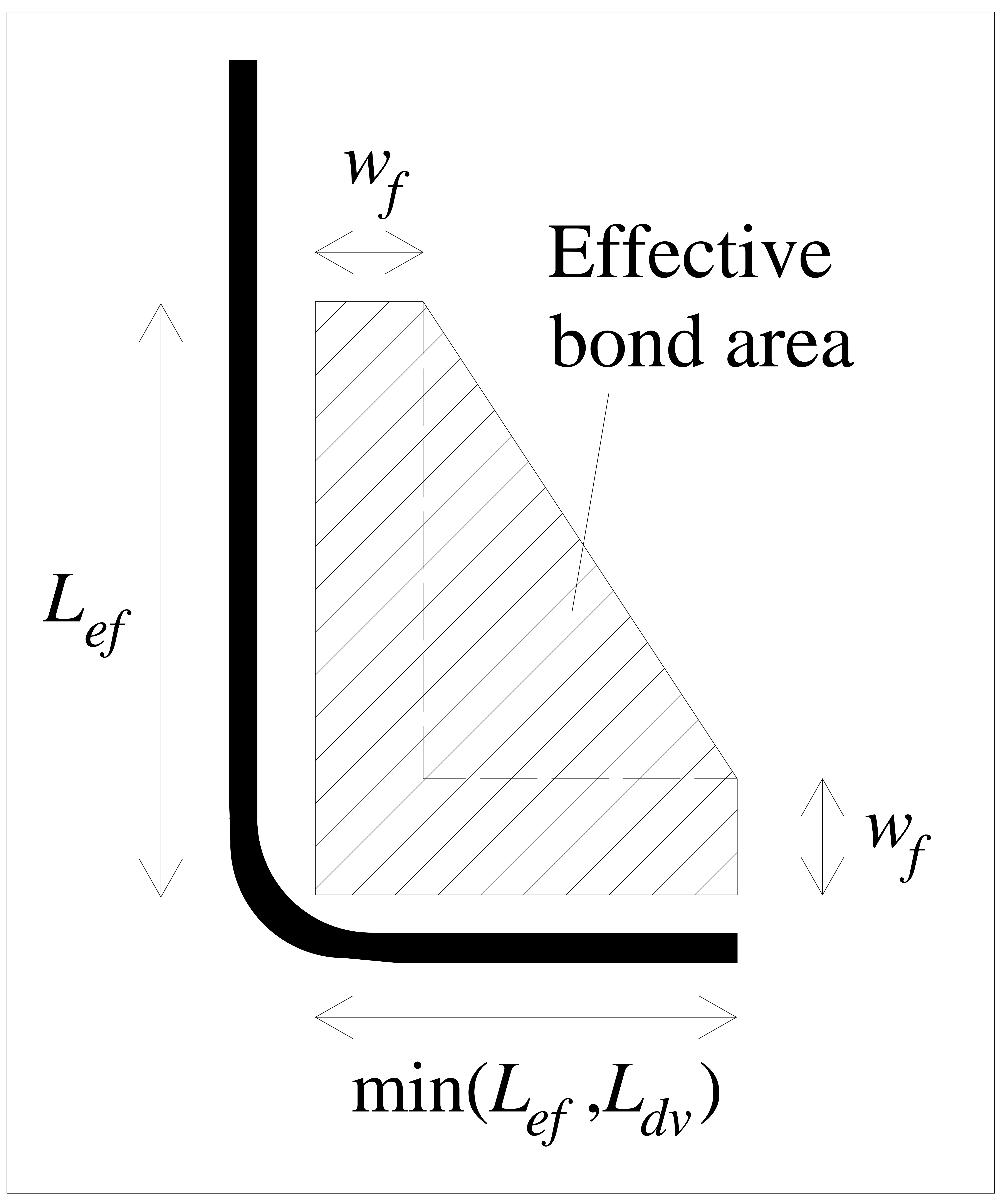

